\title{
Introduction
}

\section{Culture and democracy revisited in the global information society: Summary of a position paper}

\author{
Jacques Berleur \\ Programme Committee Chairman \\ On behalf of IFIP-WG9.2 \\ Institut d'Informatique, Facultés Universitaires Notre-Dame \\ de la Paix, Rue Grandgagnage, 21, B-5000 Namur, Belgium \\ Phone: +328172 4976, Fax: + 3281724967 \\ Email: jberleur@info.fundp.ac.be
}

\section{INFORMATION SOCIETY AND GLOBALIZATION}

The background to many of today's questions is dominated by what is now called the process of globalization of economy and society. This phenomenon has to be distinguished from the traditional processes of internationalization and multinationalization of businesses, since it includes finance, markets and strategies, technology and its related research and development, lifestyles and consumption patterns with their consequences for culture, regulatory capabilities and governance, as well as political unification of the world". 'Globalization refers to the multiplicity of linkages and interconnections between the states and societies which make up the present world system ${ }^{3}$. This development is more than an economic or technological process. It gives freedom to capital and labour to move across political boundaries, anywhere in the world. It identifies a global world by playing on intrinsic cultural variables of identity, namely space and time. The socalled global world is most probably not the whole world, but the metaphor has its importance in terms of culture. Delocalization is not recent, it has roots in the past; but what is new, even in the developed countries, is the de-linkage of the poorest regions and countries from the networked and interconnected ones. What also emerges is the penetration of more and more merchandized culture where 
culture is identified with cultural goods and services and no longer with the content through which peoples control their own identity and history.

Globalization is ambivalent. Global world, global village sounds nice in terms of linking people together, and allowing them to overcome distance as well as time. But if competitiveness is the guiding principle called to govern visions, strategies, and actions, we are assured that some of today's trends will be accentuated in the future. The scenario of the global world is the scenario of 'winners': expanding monetary speculative movements, growing poverty of some of the world's population, de-linking between rich countries and the rest of the world (the 'triadic alliance'), criminality, drugs, despoliation of common resources, radicalization of fundamentalisms of different kinds, and so on. There is no doubt that this scenario of the global world will lead to a vision which looks more like chaos than utopia.

There is no doubt that information and communication technology has played its part and contributed to this process of globalization: it has made possible such developments as the globalization of financial markets, videoconferencing, telework, telemarketing and teleshopping, just to mention a few. The Internet could be considered an emblematic symbol of this 'unified' world where - it is claimed - everyone has access to any information which they need.

\section{CULTURE}

Two words appear frequently when we discuss the future of our societies in a global information society: culture and democracy.

The discussion about the so-called White Book of the Commission of the European Communities on Employment, Growth and Competitiveness shows that public policies on information and communication technologies (ICT) networks have to anticipate substantial qualitative societal changes ${ }^{4}$. This is a must if they are to bring the necessary externalities for a real development of a new information society.

Empirical evidence shows that the link between growth and employment is all but obvious, and that new insights have to be provided so that we focus not only on economic activity and income policies, but also on social factors such as social integration and personal identity. 'Growth of the service economy as a component of the information society needs to be related to the political and cultural systems which stand for social cohesion. It is clear that the view prevailing in the media and in the official administrations that cultural and political obstacles must be removed to allow economic growth, needs to be reassessed both for the postindustrial countries and for the developing countries, ${ }^{, 5}$.

From another point of view, no one can forget the clear warning given us by Neil Postman. The problem in the first world today is no longer information scarcity, but information chaos, information without meaning, information without control mechanisms. Postman says: 'The world we live in is very nearly incomprehensible to most of us. There is almost no fact, whether actual or imagined, that will surprise us for very long, since we have no comprehensive and consistent picture of the world that would make the fact appear as an unacceptable contradiction. We believe, because there is no reason not to believe' ${ }^{, 6}$. While 
former generations of scientists tended towards positivism, the coming generation of highly specialized experts is, in its conception of the world, tending towards irrationalism and superstition.

What are the intellectual and moral responsibilities of computer scientists and ICT practitioners in making information understandable and comprehensible? Formal mechanisms of information control were traditionally supplied by school and university. The university gave expression to its idea of what constitutes legitimate knowledge and morality. Today, the traditional control mechanisms are breaking down. What should we restore as information control mechanisms, and how? Without real understanding and knowledge, there is no possible control of the development of technology. And that is culture, that is the way we shape our own destiny and make it understandable and practicable through all the institutions, rituals, means, etc., by which we regulate our violence.

New deals require new regulation. People may be upset with present politics, new market trends in the hands of a 'happy few'. Culture remains the way to find new political and economic regulations, according to the genius of nations and particular people.

What is intriguing, in our present age, is the paradoxical claim for both universal and particular, global and local. Maybe the claims are in different mouths. Nevertheless, there is a need for reconciliation between what seem to be extremes. Diversity of cultures is advocated as the only means for personal reappropriation of what has been 'stolen' by external driving forces. 'The danger of radical breaks in societies, which keep the traditional ignorance against technological development, including the polarized position of complete rejection or uncritical acceptance, lies in severe damages to global cultural diversities: worldwide acting information, communication and media technologies tend to unify the cultural perceptions, leaving little room for regional or national accents and historically grown peculiarities. Sustainable cultural development needs an open debate, and this means before all, it needs sufficient time - time for thought, understanding the challenges, and evaluation, and time for planning, action and correction,?

Respect for cultural diversities and differences, need for more precise visions of the future, preservation of culture, information overflow, and capacity of interpretation according to different human perception patterns are necessary to preserve us from the ambivalence of globalization. There is no control out of an understanding space.

\section{DEMOCRACY}

When speaking of information society from a 'political' point of view, many people stress different dichotomies: developing and developed nations, women/men, young/old, computer literates/illiterates, rich/poor, able/disabled, minorities/majorities, technophobia/technophilia, etc. Others act to 'empower people'. FreeNets and other Digital Cities are presented as democratic tools for public participation in the building up of the information society and for meeting public needs. Discussions about universal access to information infrastructure are going on all around the world. Personal participation in the civil society is 
diminishing. Are civil rights not threatened by the integration of formerly separate technologies? Democracy is at stake when contemplating information society development.

The merging of big businesses all around the world, such as between Time Warner and Turner or the two Baby Bells, Bell Atlantic and Nymex, or British Telecom and the Italian Mediaset, one of Berlusconi's holdings, etc., is also felt as domination by a few when it is not a threat against any possible state regulation.

Reactions to the United States' National Information Infrastructure (NII) Agenda for Action, as well as to the G7 Global Information Infrastructure (GII) Project or to the European Bangemann Report highlight the issues at stake in terms of governments' roles, participation of the citizen, protection of nonprofit sectors, etc.

The lack of consensus on the way economics and politics are handled and envisaged reveals opposing visions and ethics and requires closer relationships, and a kind of conviviality, in order to recreate spaces for democratic discussion. The post cold-war period has revealed, if not created, a state of affairs where democracy is on trial ${ }^{8}$. Devolution is in the air. The social fabric has been torn to pieces and has to be woven again by recreating social spaces and social solidarities, in order to restore a common language and build up consensual decision-making. History shows that the weakening of the middle-class - what could be translated in firms in terms of an impoverishment of intermediate positions, especially due to ICT diffusion - results in a totalitarian regime. The development of a nation is due to the strength of its social fabric, its related institutions, and the presence of a well trained middle-class. Fracturing communities and exaggerating self-realization is an anti-democratic process which will most probably lead to the explosion - a chaos? - of societies.

'Democracy in Cyberspace' would at least maintain and develop some specific roles for governments, as was emphasized in the mid-1990s in one of Britain's responses to the information superhighway. Let us mention these proposals: create a coordinated focal point for debate and action; position the information superhighway strategy at the centre of socio-economic policies to ensure it is allocated sufficient priorities and resources; establish effective processes to develop and enact national and international legislation that takes account of the new capabilities of interlinked applications and the speed of technological innovation; ensure government has the authority and resources to assert and monitor the protection of public interests in applications and developments; find suitable mechanisms to support nonprofit 'public interest' applications; seek novel and effective means of encouraging social and organizational innovation in the use of the new ICT; drive innovative applications by using networks to offer a greater range of direct electronic service delivery of public service; and develop appropriate policies for supervising new media regimes, avoiding the growth of multimedia and transnational monopolies?

\section{CHALLENGES FOR OUR CONFERENCE}

There are many challenges which lie ahead in the development of a global information society. Culture and democracy are two areas which may be under 
particular threat. It is the proposed role of IFIP-WG9.2 and colleagues to analyze and define the relationships underlying information, globalization, culture and democracy, and to provide to the information society's major decision-makers possible options for future solutions and actions.

\section{LET US GO FURTHER ...}

This paper was written for the call for papers. It accompanied it to encourage suggestions, comments, and remarks from the different contributors. This means it dates back to when most of the official documents on the global information society were still not well known or even in their infancy. The most important European documents, for instance, date from June 1994 to mid $1996^{10}$. Is it not worth seeing how important the main themes of our conference were considered to be in the official documents?

\section{PERSPECTIVE OF OFFICIAL DOCUMENTS}

What about the information society itself? A document, at our disposal on the official Information Society Project Office (ISPO) site, raises the question 'What exactly is the Information Society?' The answer is given as follows in an attractive box (We quote 'exactly') ${ }^{11}$ :

- Basic network (physical network + basic functions)

- Generic services (e-mail, data base access, interactive video)

- Applications (telework, telemedicine, telebanking, etc.)

We leave the appreciation of this definition to the reader, but we personally have doubts about the interest of the document's authors in societal questions, when these are spelled out solely in technological terms!

Regarding the interest of officials in democracy and culture, let us have a look at a word count. We know that counting words is not always statistically significant and that ideas or concepts may lie behind other words ... but!

Table 1 is eloquent in itself. Let us stress that, when looking at the market, the Bangemann report underlines what is already explicit in the word count: the report's second chapter is entitled 'A market driven revolution'. We must add that the term culture which seems to be the most important covers expressions such as: culture and leisure activities, cultural traditions and identities, the new information culture and its instruments, multiplicity of cultures and languages, international property rights and wide variety of industrial and cultural sector, without referring at any time to the meaning that we have tried to enlighten. Let us not forget that the European Community is attempting to envisage a Way to the Information Society. 
Table 1. Word count in official documents

\begin{tabular}{lcccc}
\hline & $\begin{array}{c}\text { Bangemann } \\
\text { Report }\end{array}$ & $\begin{array}{c}\text { Action } \\
\text { Plan }\end{array}$ & $\begin{array}{c}\text { Rolling } \\
\text { Action } \\
\text { Plan }\end{array}$ & $\begin{array}{c}\text { US - NII } \\
\text { Agenda for } \\
\text { Action }\end{array}$ \\
\hline Democracy, democratic, ... & 0 & 0 & 2 & 2 \\
Culture & 7 & $13^{*}$ & 5 & 0 \\
Language - Linguistics & 3 & & & 0 \\
Economy, economics & 14 & & & \\
Market & 110 & & & \\
\hline
\end{tabular}

* (five times in titles)

When we look at the actions and policies of the first European Action Plan (July 1994), we may wonder how important societal, social, and cultural aspects are! Table 2 shows the number of actions and policies explicitly envisaged, according to four main headings.

Table 2. Number of actions and policies in the European Action Plan

Regulatory and legal framework 54

Networks, basic services, applications, and content 27

Social, societal, and cultural aspects 5

Promotion of the information society 11

The later Rolling Action Plan (November 1996) changed the classification. The content of Table 3 could seem more satisfactory, since the number of actions regarding 'People at the Centre' has been increased considerably compared to the social actions of the first Action Plan. (Here, we have combined the forthcoming, pending, and ongoing actions.)

Table 3. Number of actions in the European Rolling Action Plan

Improving the business environment

47

Investing in the future

13

People at the centre

28

Meeting the global challenge

16

The contents of these tables 2 and 3 should be scrutinized very carefully. Curiously, actions which were classified in the first Action Plan under 'regulatory and legal framework' find their place in the Rolling Action Plan under 'people at the centre'. The title is nice, but it is not a reason to be rolled like meatballs in flour! It covers so many different items, such as green papers, directives, guidelines, and so on, that it is not very easy to find out what are the main features which will place people at the centre. But the preoccupation must be welcomed.

As recognized in the January 1996 Report of the High Level Expert Group (HLEG), 'social policy (...) merits equal if not more weight than economic policy in formulating our approach to the Information Society (IS). We believe that the Commission has paid insufficient attention to these issues so far, ... "12 'The Group welcomes the Commission's initiative to provide a major impulse into the broader 
policy debate surrounding the emerging IS, by setting up the HLEG. So far, the IS policy debate has been dominated by technological issues and more recently the appropriate regulatory economic environment, neglecting by and large, some of the broader issues implicit in the "society" notion",

The first evaluation by the European Commission, which took place in Essen, after the Corfu 1994 endorsement of the Bangemann Report by the European Council, recognized the necessity of looking more carefully at the social, societal, and cultural aspects of the global information society. It was decided to create two new instruments to assist the Commission: the above-mentioned HLEG and the Information Society Forum ${ }^{14}$. Both groups reported in 1996 (in January and June respectively), but there is no evidence that they deeply influenced the Rolling Action Plan of November 1996, although the 1995 Essen conclusions proclaimed that they would 'assist the Commission in the preparation of its actions' ${ }^{15}$ ! The focus, as stated in the same conclusions, was important, but somewhat narrow when it spoke about priority measures mainly in terms of: 'Impact, qualitative and quantitative, of the introduction of new information and communication technologies on employment, and conditions for optimal exploitation of new sources of employment linked to technological progress', or 'Impact of new technologies on work organization (flexible enterprise, teleworking) and potential consequences on social legislation (labour law, social security, including health and safety at work)', etc. All the measures are expressed mainly in terms of adaptation to the consequences of situations which would have happened already, and are surely not expressed in terms of controlling our own future.

\section{ISSUES AT STAKE}

The issues at stake are difficult to assess, but certain trends are already there which require our full attention. The world flow of trade in the globalized world is obvious, and the competition is sharp. That cannot be hidden. But what needs to be shown too is the whole picture. In fact, what the figures show is that from 1970 to 1990 in the triadic countries, regional trade flow in terms of manufactured goods (as a percentage of world trade) increased from $60.9 \%$ to $73.6 \%{ }^{16}$. This means that there are losers, and here they are clearly: Latin America, Africa, the Middle East, central and eastern Europe, and the former USSR. If the same trend continues for the next twenty years, those countries' share of world trade would go down to $5 \%$ !

We defined culture in terms of the way we shape our own destiny and make it understandable and practicable through all the institutions, rituals, means, etc., by which we regulate our violence. Does the present information society help culture when the so-called cultural information available on the Internet is mainly 'entertainment' ${ }^{17}$ ? Or when we are presented with such potential shopping applications as smart cards and interactive kiosks providing information to customers and keeping track of their buying habits so as to adjust inventories and to price and promote products better; intelligent carts organizing customers' shopping through the store's aisles, scanning their shopping lists at the entrance; in-store kiosks, with 'electronic mirrors' with holographic images enabling buyers to see what clothes look like on them without trying anything on; etc. ${ }^{18}$ ? We 
know there are more justifiable and defensible applications, but are these also in the mind of our futurologists?

What about democracy? Let us just remind ourselves of the declaration of the Computer Systems Policy Project, a group of chief executive officers of the thirteen largest north American computer companies at its meeting of February 13, 1995, in preparation for the G7 February 25-26, 1995 Information Society Conference in Brussels: 'Let us put the private sector in the driver's seat'1 statement is true, but surely democracy is endangered as soon as the public space, which is the key concept of democracy today, is monopolized or captured by a single actor. Policy-makers have reacted immediately, as mentioned already in Britain's response to the information superhighway which urges appropriate government roles. The same accents are coming from those who demand global sustainability in the 'development for 8 billion people ${ }^{20}$.

Let us repeat again: 'It is clear that the view prevailing in the media and in the official administrations that cultural and political obstacles must be removed to allow economic growth, needs to be reassessed both for the post-industrial countries and for the developing countries' (emphasis added).

\section{CONCLUSION}

Globalization, culture and democracy are only words, but they are very important words. This conference aims at clarifying their meaning in the present situation and at seeing where we stand.

That is why, IFIP-WG9.2/9.5 raised in its call for papers some questions which do not have to be answered as such, but which constitute a background to our common questioning:

- How can we cope with the sustainability of society if we are unable to understand and anticipate its cultural, social, political, economic and technological developments?

- What happens to jobs and work-related skills when we face the integration of the different components of ICT unaccompanied by vocational retraining?

- What does it mean for everyone to access information when its diffusion is shaped in a monocultural way?

- How can people stay in control of their development, if it is not deeply rooted in their own culture?

- What is the significance of technological developments that do not meet the needs of society?

- How is democracy affected by the declining power of political discourse resulting from the increasing power of liberal market driving forces?

- Are there specific threats to civil rights from certain technologies and especially from the integration of what were formerly separate technologies?

Corfu is where the Bangemann Report was accepted by the European Council summit meeting on June 24-25, 1994. Since then, questions have emerged about the future of the global information society. We could try to remind ourselves of the first steps in moving towards the global information society and revisit them. And make a step forward: From Corfu 1994 to Corfu 1997. 
1 The author is also a member of the 'Cellule Interfacultaire de Technology Assessment' (CITA) which is financially supported by the Belgian Federal Office for Scientific, Technical, and Cultural Affairs (Interuniversity poles of attraction, Phase IV).

2 The Group of Lisbon, Limits to Competition, Gulbenkian Foundation, Lisbon 1993. Published by MIT Press, 1996 (ISBN 0-262-07164-9), 176 p. Translated into French (Ed. La Découverte, Boréal, Labor, 1995), Italian, Portuguese and Swedish (Ordfronts Ferlag, 1996). Anthony G. Grew, Paul Lewis et al., Globalisation and the Nation States, Polity Press, Cambridge, 1992, p. 22.

4 Commission of the European Communities, Employment, Growth and Competitiveness, Brussels, December 5th, 1993, COM(93), $700 \mathrm{p}$ final. Published as a book: Jacques Delors, Pour entrer dans le XXIème siècle. (Emploi-Croissance et Compétitivité. Le Livre blanc de la Commission des Communautés Européennes), Paris, Michel Lafon - Ramsay, 1994.

5 Gonzales d'Alcantara, Information Overflow - Problem Solving Methodology, in: Information Processing '94, vol. III, Linkage and Developing Countries, Karen Duncan and Karl Krueger, Eds., Proceedings of the IFIP 13th World Computer Congress, Hamburg, Germany, 28 August 2 September, 1994, North-Holland 1994, IFIP Transactions A-53, p. 206.

$6 \quad$ Neil Postman, Technopoly: The Surrender of Culture to Technology, New York: Knopf, 1992.

7 Wolfgang Coy, Cultural Stability and Technological Change: The Case of Information, Communication and Media Technology, in: Information Processing '94, vol. III, op. cit., p. 217.

8 Jean Bethke Elshtain, Democracy on Trial, New York: Basic Books, 1995.

9 The Information Superhighway: Britain's Response, A Forum Discussion, by W. Dutton, J. Blumler, N. Garnham, R. Mansell, J. Cornford and M. Peltu, Paper No. 29, Programme on Information and Communication Technologies, Economic and Social Research Council, Brunel University, UK, December 1994. See also: http://www.isi.gov.uk/isi/dbitis/nat_strat.html

10 Commission of the European Community, Europe and the Global Information Society Recommendations to the European Council - The Bangemann Report, 26 May 1994, CD-84-94290-EN-C. Commission of the European Community, Europe's Way to the Information Society. An Action Plan, Communication from the Commission to the Council and the European Parliament, and the Economic and Social Committee and the Committee of Regions, Brussels, COM(94) 347 final, July 19, 1994. Commission of the European Community, Europe's Rolling Action Plan for Information Society, COM(96) 607 final, Brussels, November 27, 1996. Building the European Information Society for Us All, First Reflections of the High Level Expert Group on the Social and Societal Aspects of the Information Society, Interim Report, January 1996. Commission of the European Community, Networks for People and their Communities. Making the most of the Information Society in the European Union. First annual Report to the European Commission from the Information Society Forum, Luxembourg, Office for Official Publications of the European Communities, CD-96-96-473-EN-C, ISBN 92-827-7805-3.

11 http://www.ispo.cec.be/infosoc/backg/action95.html (April 28, 1995, C) ECSC-EC-EAEC, Brussels - Luxembourg, 1995).

12 Building the European Information Society for Us All, op. cit., Executive Summary.

13 ibid, Introduction, p. 1.

14 The Essen Conclusions (1995). See: http://www.ispo.cec.be/infosoc/backg/essen.html

15 ibid.

16 Ugur Muldur, Les formes et les indicateurs de la globalisation, FAST, Commission des Communautés Européennes, 1993. Quoted in: The Group of Lisbon, Limits to Competition, op. cit. (French edition, p. 136).

17 See, for instance: (Contents according to Yahoo, on 95.07.23).

http://www.cern.ch/CERN/WorldWideWeb/Intro/PresentationsF/General/ContentCategories.html

18 Barrett Seaman, The Future is already there, in TIME, Special Issue: Welcome to Cyberspace, Spring 1995.

19 Vigdor Schreibman - FINS (fins@access.digex.net), FINS Special Report, February 21, 1995, Public-Access Computer Systems Forum (pacs-1@uhupvm1.uh.edu).

20 The Common Global Sustainability by Co-Determination and Co-Development. The 47 Major Priority Areas for Science and Technology for the 8 Billion People, CAN-MONITOR Meeting, March 5, 1993, FAST Programme, Theme C: 'Global Perspective 2010: New Tasks for S\&T'. 